\title{
The future of work: Remote work in the emerging new normal
}

\author{
Simon J. Best
}

Medgar Evers College, City University of New York, USA

\author{
Keywords \\ Burnout, Future of Work, HRM, Hybridization, New Normal, Psychological Safety, Remote \\ Work
}

\begin{abstract}
What HRM structures and schedules are most likely to characterize the post-pandemic period? This paper, taking a multidisciplinary approach to the analysis of the future of work and hybridized workforces, straddles the fields of HRM, business economics, and organizational behavior. It seeks to provide insights into the evolving post-pandemic's new normal. The gains from the vaccination efforts in the US, in particular, are leading to shifts from the pandemic's dismissal as a short-term phenomenon, to one that is now manageable. This paper, hence, analyzes the emerging trends and patterns that will most likely influence and shape the use of the human resource in companies, especially within the United States of America. It highlights the various discovered types, intensities, modalities, related to a range of worker types and work conditions associated with hybridized HRM, and the expected patterns and changes in employer-employee relationships likely to be maintained or expanded, that, informed by the Gratton framework of time and place. The paper maintains that not all work types are suitable for remote work. Additionally, certain gender biases are retained in the pandemic induced HRM hybrid models, while some are even reinforced. New work-life balance issues have also entered into work structuring and scheduling arrangements, with implications for the education attainment of the young and underserved, especially if, for example, hybrid education delivery becomes more widespread. The paper concludes with suggested research recommendations prompted, in part, by the pandemic's workforce and HRM challenges.
\end{abstract}

\section{Introduction}

Whether it is called long-distance working, working from home (WFH) (see Sawhney, 2021), telecommuting, working from anywhere (WFA) or working from office (WFO) (see Gratton, 2021), telework or remote work, depending on who is the speaker, to some it is an aberration (K@W, 2020). To others, it is a revolution (see Neeley, 2021). Throughout the several waves of the pandemic, acceptance and adoption of variations of hybrid models of in-person and remote work by companies have become the norm. A remote work survey in 2021 reported that $82 \%$ of Americanbased companies were planning to implement indefinite WFH models, while $77 \%$ wanted to make WFH permanent (Simform, 2021). In the context of the waning of the pandemic, which forms the backcloth to the emerging new normal, a V-shaped economic recovery is seemingly gaining steam in the US economy, with an expectation of a near annual 6\% GDP growth rate, after the pandemicinduced economic decline. Since the Biden Administration's rescue plan, the labor market has generally shown an uptick in growth, with the unemployment rate tracking down to 6.0 percent (BLS, 2021). Related background information suggests an inflation rate higher than the Federal Reserve's $2 \%$ target, with signs of an increase, but no runaway inflation in the short- to mediumterm period.

Regarding methodology, this paper has been assembled from many secondary sources. However, the information presented intends the provision of some insights regarding an improvement in the understanding of emerging trends, the rationale for the variations in hybrid work models in place, and declarations to formally adopt or to extend on what currently exists. In addition, it seeks to address the 
likelihood of the retention of elements of the various HRM models, going into the future, either in their entirety or in combination, as influenced by the control of the virus and its variants.

As such, this paper examines some of the concepts associated with the hybrid models created or intended by various firms. This is covered in the upcoming section. Following this is a very brief presentation of the nature, range and plans for a more formal adoption of the hybrid HR model by various companies, in several industries and in different economic sectors, but with the main focus on the US. This review, however, is not based on a company list, and makes no claims to be either exhaustive or comprehensive. In the following section is a discussion of some of the upsides and downsides of existing hybrid models. The paper concludes with some research recommendations regarding the road ahead.

\section{Conceptual Framework: Understanding Hybridity}

The forced decentralized approach to the use of HR and the associated hybridity models of HR utilization, display a range of workforce members working remotely and at home, informed by their employers' needs and experiences with the pandemic. Retention of some elements of existing models is generally assumed. However, the current level of adoption is not. Therefore, hybridization represents a mix of in-person and remote workers in a workforce, working synchronously and/or asynchronously, but lies at some intersection of time and place (see Gratton, 2021). If effectively executed, it is argued that a hybrid future will redound on both the workers and their employers, allowing for a more purposeful work-life, greater flexibility, improved agility, and enhanced productivity. Increasingly, for some companies, however, a more formal adoption is regarded as a given. For example, and for certain businesses, culturally speaking, work-at-home Fridays can become the norm. However, some companies want at the same time, to ensure that one day in the workweek is set aside where staff can all be present in office (if necessary) within a slotted time. In this regard, a number of firms have taken concrete steps to plan for the formal adoption of the hybrid HRM model with the reopening of the US economy (K@W, 2021; Neeley, 2021).

The Gratton (2021) Framework suggests that conceptually, hybrid work can be perceived to be taking place in terms of two dimensions: place and time. A four-quadrant analytical framework can be derived with time on one axis and place on the other, when those are further subdivided into being placeconstrained, meaning, working in-person from the office (WFO, work-from-office workers, or WFOs) (see Choudhury et al., 2019). At the polar opposite end, place can be unconstrained. Working under the condition of unconstrained place would be those WFA (work-from-anywhere) workers, such as some taxi drivers and teleworkers or the emerging digital nomads (Everson, King \& Ockels, 2021). Regarding the time dimension, employees are either more time-constrained, that is, having to work with others at the same time, or can be time-unconstrained. The latter group represents the ATWs (any-time workers). As such, they could be working asynchronously at different times (working with others, even in different time zones within or outside national boundaries), or whenever they please, such as those in gigging work relationships (domestically or internationally), or passing on semifinished work to others for completion in other time zones as members of virtual teams. For those who can work as part-time independent contractors, in particular, remote work offers the opportunity for international gigging. This especially allows for employers, to choose from a wider pool of talented workers from almost anywhere around the world (see Best, 2017). 
Figure 1 below adapted from, and hereinafter sometimes referred to as the Gratton (2021) Time and Place Framework, and from the writings of O'Hara (2014) and Sawhney (2021), takes a more expanded labor utilization or focused employment perspective, to specifically isolate various worker types and characteristics, based on the working and contractual relationships between employers and employees, by firms forced to follow a more or less formal hybrid HRM employment strategy. It reclassifies workers as work-from-office workers (WFOs), or WFO workers and work-fromanywhere (WFA) workers or WFAs, with finer distinctions being made according to the times those workers are either expected or required to be on the job, or at their jobs. Section 1 in the figure therefore, shows the traditional and largely pre-pandemic (9-to-5) FTWs (fixedtime workers), made up of regular workers who "report to work" (sometimes by logging in), as members of in-person teams, part-time, and gigging $\mathrm{C}$-suite workers. It is noteworthy that gigging has moved into the $\mathrm{C}$-suite, as some companies have been employing temporary and part-time workers at the Csuite level, sometimes showing up for three out of five days per workweek, as senior marketing personnel, even before the onset of the pandemic. This work pattern is very likely to persist postpandemically for some WFA workers (see Best 2017; Kalita, 2021).

Following Gratton's constrained time but unconstrained place classification, as found in Section 2 of Figure 1, would be the working conditions for today's hybrid workers who complete 9-to-5 worktime schedules as fixed-time workers (FTWs), but working from anywhere, (sometimes referred to as WFH or WFA workers). These could be regular employees, part-time workers, and virtual teams on the regular payroll of companies. Section 3 in the figure identifies the hybrid worker types that are unconstrained by time, but are constrained by place, as would be in the Gratton (2021) framework. Such workers are constrained to work at the office (WFO), but theoretically can work there at any time (as anytime workers, or ATWs). Worker types that belong to this group can include regular workers (employees working under the normal psychological contract), in-person teams, part-time workers and gig workers. Finally, workers in Section 4 would include those workers who may be forced, or have elected to work anytime (as anytime workers, or ATWs) and from anywhere WFA (work from anywhere) as found in the Gratton framework. In this group, one would expect to find virtual teams (domestic and international), some part-time and contract workers, independent contractors, and gig workers (domestic and international). 


\section{Hybrid Worker Types and Environments: An Employment Perspective Based on} the Gratton's Time and Place Dimensions

\begin{tabular}{|c|c|}
\hline $\begin{array}{l}1 \text { Constrained (Fixed) Time and Constrained Place } \\
\text { Traditional 9-to-5 workers ( some WFOs, FTWs) }\end{array}$ & $\begin{array}{l}3 \text { Unconstrained Time with Constrained (Fixed) Place } \\
\text { In office, any time workers (WFOs, ATWs) }\end{array}$ \\
\hline $\begin{array}{l}\square \text { Regular workers (using psychological contracts) } \\
\square \text { In-person teams (Fixed) } \\
\square \text { Part-time workers } \\
\square \text { C-suite workers engaged in gigging (with fixed roles, } \\
\text { such as marketing managers for start-ups) }\end{array}$ & $\begin{array}{l}\square \text { Regular workers (with flexible time schedules) } \\
\square \text { In-person teams (with flexible ime schedules) } \\
\square \text { Part-time (in office or on location) workers } \\
\square \text { Gig workers (with flextime but working on location) }\end{array}$ \\
\hline $\begin{array}{l}2 \text { Constrained (Fixed) Time with Unconstrained Place } \\
\text { Traditional 9-to-5 workers (some WFAs) }\end{array}$ & $\begin{array}{l}4 \text { Unconstrained Time and Unconstrained Place } \\
\text { Anywhere, AnyTime Work (some WFAs, ATWs) }\end{array}$ \\
\hline $\begin{array}{l}\text { Regular workers (using psychological contracts) } \\
\text { Part time workers (theoretically WFA) } \\
\text { Virtual teams (working in different places, } \\
\text { synchronously or asynchronously, in the same or in } \\
\text { different time zones, in or out of one country) }\end{array}$ & $\begin{array}{l}\square \text { Virtual teams } \\
\square \text { Part-time and contractual workers } \\
\square \text { “Independent contractors” (subject to legislative } \\
\text { change) } \\
\square \text { Gig workers (international and local) }\end{array}$ \\
\hline \multicolumn{2}{|c|}{ Sources: Adapted from Gratton (2021), O'Hara (2014), and Sawhney (2021) } \\
\hline
\end{tabular}

Figure 1: Sources: Adapted from Gratton (2021); O'Hara (2014); and Sawhney (2021)

In addition to the given perspectives with respect to time and place, two other key factors operating in hybrid environments are: a) hybridity positioning, and b) hybridity competence. Mortensen \& Haas (2021) maintain that key sources of power and influence, emerging from access to resources and different levels of visibility, depend on hybrid positioning. The authors also contend that with respect to hybridity competence, operating effectively in a hybrid environment becomes a source of power. It is a skill in and of itself. Additionally, those with the ability to work in such a workforce, may well outperform those recognized as having "advantaged positions," if in the low visibility parts of the workforce, they show others that they are trustworthy.

Labor productivity remains a major concern whatever the work schedule, the work pattern, or the associated technology. Regarding teleworking as remote work, a key focus of today's hybridization, the Dutcher (2012) study with respect to teleworking reported contradictory claims. However, differences were observed in that study regarding environmental impacts with respect to dull and creative tasks, with creative tasks showing then greater promise for productivity improvement. Arguably, and as illustrated in Figure 2 below, where people work, in terms of time and place, is a function of: a) their psychological and legal contracts, and $b$ ) their job types. 


\section{I he tuture of work: Remote and in-person conditions \\ Arguably, where people work, in terms of time and place, is a function of: \\ a) their psychological and legal contracts, and \\ b) their job types}

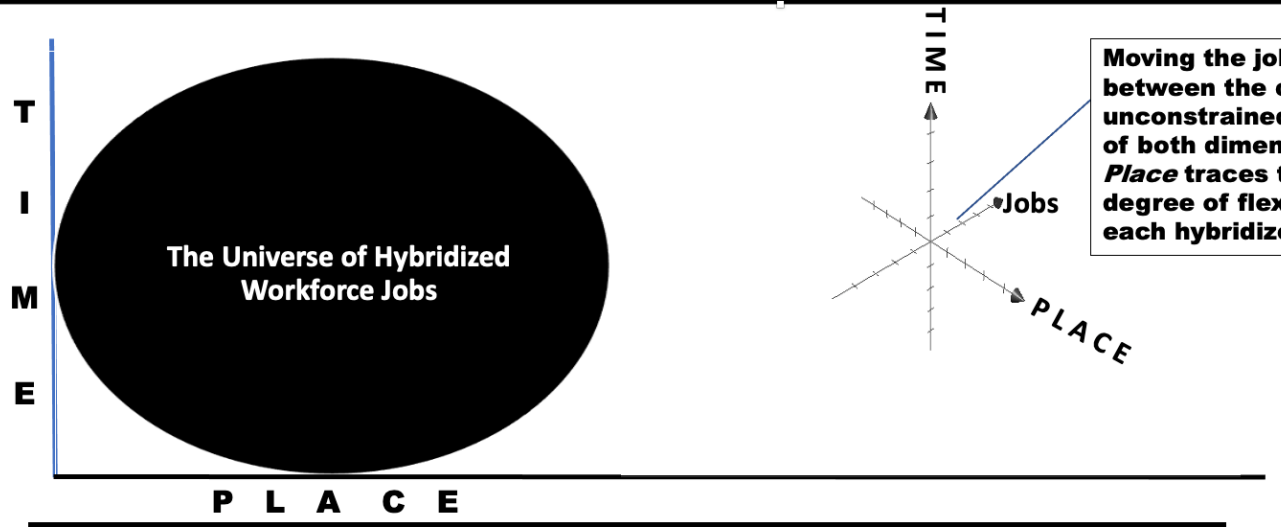

Figure 2: Tracing the Range and Flexibility of Hybridized Workforce Jobs

\section{Some Factors Shaping the New Normal}

A number of factors and developments for economic, technological, and for political and security reasons are expected to influence greatly, future hybrid work patterns domestically and around the world. Among them are cost savings on office space, the search for productivity increases, the need for agility and flexibility, and the sourcing of talent regarding skill shortages.

Savings Regarding Real Estate Expenditures. In keeping with the policy change to retain a significant number of WFH-type workers, a number of firms have been studying their use of real estate in terms of office space in a post-pandemic world. In this regard, Gartner (2021) in a recent survey, anticipates that some companies will be engaging in shared seating.

Table1 below, without claims to being either exhaustive or comprehensive, attempts to capture some company initiatives, associated industries and/or the related economic sectors around the world. It shows those companies that are in the process of formal workforce hybridization, and what their plans are. Those with intentions to retain some form of hybridization, with some notion of permanence are also included. Nevertheless, the rate and type of adoption of formal hybridization of the workforce at the company level will depend, in part, on the degree of national control of the spread of the virus and its variants, together with the level of success with population immunity. The resistance to vaccination especially by the younger age cohorts in the population, in face of the increasing occurrence of variants has implications for the forms and rates of adoption of hybridization, and for technology substitution for labor shortages, together with the longer term social security burdens of providing for the needs of older population cohorts. 
Table 1: Some Companies in Transition to Formal Adoption of Hybridization

\begin{tabular}{|c|c|c|}
\hline Company & Sector/Industry & Action/Activity/Outlook/Plans \\
\hline Box & Internet & $15 \%$ of workforce post-pandemically on full-time basis \\
\hline CDLP (Stolkholm) & Fashion & $\begin{array}{l}\text { Restructuring to locate } 50 \% \text { remote workers around the } \\
\text { world }\end{array}$ \\
\hline Coinbase & Finance & $\begin{array}{l}\text { Anticipates } 20-60 \% \text { and more over time remote } \\
\text { workers, with restrictions lifted }\end{array}$ \\
\hline $\begin{array}{l}\text { Facebook, Spotify, Microsoft, } \\
\text { Salesforce, Twitter, and Slack }\end{array}$ & Social Media & $\begin{array}{l}\text { Rolled out plans for a long-term remote workforce beyond } \\
\text { just } 2021 \text { Thiefels (2021). }\end{array}$ \\
\hline Google & Media & Advancing moves to bring back workers to the office \\
\hline J P Morgan Chase & Banking & Considering a permanently remote workforce \\
\hline Nationwide Insurance & Insurance & $\begin{array}{l}\text { To transition to remote workers at } 16 \text { of its } 20 \\
\text { locations }\end{array}$ \\
\hline Nielson & Media & Staff complement of 3000 will work mostly from home \\
\hline PSA Group (Europe) & Car (Auto) & $\begin{array}{l}\text { Non-production staff to shift to remote work (agility } \\
\text { strategy) }\end{array}$ \\
\hline $\begin{array}{l}\text { Tata Consultancy Services } \\
\text { (India) }\end{array}$ & Services & $\begin{array}{l}\text { Anticipates } 75 \% \text { of its workforce to be working } \\
\text { remotely by } 2025\end{array}$ \\
\hline UBS (Switzerland) & $\begin{array}{l}\text { Banking/Wealth } \\
\text { Management }\end{array}$ & $\begin{array}{l}\text { One-third of employees to work remotely permanently, } \\
\text { offering staff a mix of working from home and the } \\
\text { office on a permanent basis to attract talent }\end{array}$ \\
\hline Sou & : Neeley (2021) & efels (2021); and Clayton (2021) \\
\hline
\end{tabular}

The Working from Home (WFH) Option. For O'Hara (2014), this includes the benefits of: a) flexibility, b) autonomy, and c) the comfort of working in one's own surroundings, among other things. However, there are upsides and downsides associated with extended periods using the WFH option. Sawhney (2021) maintains that some of the by-products of such work environments include monotony, social isolation and burnout. Granted the new hybrid forms with multi-located parts of a company's workforce, post-pandemic hybrid HRM is expected to undergo several changes. However, research shows that a work setting suitable for remote work has to be fairly independent, and at the same time, employees need to have the knowledge base to do their work well. In such situations, both the employers and employees stand to benefit from the job relationships (Choudhury et al., 2019; Mortensen \& Haas, 2021). 
Work Performance and Productivity Improvements. The change to greater work flexibility has had a positive impact on productivity, depending on the business type. Neeley (2021) for example, states that J P Morgan Chase experienced a three-fold increase in worker productivity from its traders working from home. UBS, a Swiss lender, has adopted a formal hybridization policy in an attempt to attract talent by enticing workers away from Wall Street bankers, offering prospective candidates and up to two-thirds of staff a mix of working from home and the office on a permanent basis. This shows a marked contrast and departure from the positions taken by some US Banks. For UBS, only those employers where conditions set by supervisory rules, or the need for the execution of specific tasks, would cause them to have to forgo the work flexibility on offer (Walker, 2021).

Moss (2018) states that for working parents with children, job flexibility, where workers can choose the place and set their own working hours, (the combined WFA, and ATWs situations in Section 4 in Figure 1 above) have been found not only to increase gratitude, but also to improve job satisfaction, coupled with stress reduction. Here too, employees are able to experience cost savings with respect to commutes and child care (Carucci, 2021). There is also the expectation of increased worker retention and motivation. The WFA (work from anywhere) remote work variant, too, has the potential to extend the careers of valued employees, encouraging them to remain with companies. By so doing, these older employees can pass on their organizational memory to younger workers, as the former move on to more favorable climatic country areas in keeping with their health demands (Choudhury et al., 2019). Therefore, intergenerational mentoring remains a potentially positive holdover in the post-pandemic future.

\section{Remote Work in the New Normal: Some Potential Downsides}

Work-Life Separation and Work-Life Balance. Given today's labor market conditions, at what levels might office workers, in particular, be willing to return to work in a post-pandemic world? In this regard, some studies have concluded that teleworking loses its appeal in winter. In addition, for workers with a preference for strict segmentation of work and life, work-life balance remains an important issue. This has special implications for the scheduling and structure of remote work. Perhaps as segmenters, 55\% of persons in a recent study felt an inability to balance their work and home lives. For some workers, too, there is a preference for a return to work for three days per week. Others want the option of being at home, at least one day during the workweek. However, pre-pandemic workplace gender and equity issues are likely to persist. Women, more than men, appear to have a preference to work from home. Yet, if managers continue to give preference to those who they see, then women will correspondently pay a career price (see The Economist, 2021). Rather than mitigating the existing bias, such a work pattern might even serve to reinforce it.

Teleworking can cut both ways. It must therefore be recognized, that one of the downsides of teleworking or working from home can also be productivity. Some workers in the current climate face an uphill battle to stay focused on tasks at hand, in addition to remaining highly motivated when home becomes the office or the workspace. For managers then, the challenge is to keep workers motivated and to monitor them from a distance. With WFH workers, the lack of coworker proximity too, means that employees lose the benefits of the creative conversational exchanges that occur (say) at the water cooler, or along corridors, forfeiting potential serendipities. Even with the best streaming and conferencing media tools available on the market today, reportedly, it requires more assertive behavior on the part of some workers for them to remain mindful that some audience members are indeed part of the workforce. Therefore, those who work as teleworkers are very likely to suffer in the 
absence of facetime with others working under similar conditions with managers, reinforcing some of the negative influences on their promotion and their careers (see Morgan, 2021). For some, too, a sense of never being at the workplace can also translate into one of forever being at the workplace (Neeley, 2021; Tugan, 2020).

Burnout. Although, not peculiar to, or essentially tied to remote work per se, another downside associated with teleworking, is burnout. With or without a pandemic, burnout is a potential threat to worklife. For some occupations, the pandemic has increased the incidence of burnout. To compensate for some of the disadvantages of working remotely, some workers may engage in overcommitment resulting in burnout. If the incidence of burnout remains at, or goes beyond current levels going into the future, this must be addressed very seriously. Whereas research points to burnout as being a problem tilted towards the organization more than being an employee's problem, it behooves all employees to engage in preventative steps to avoid it. Besides, recovery requires teasing out and addressing its components. Therefore, in the interest of recovery, researchers have identified three symptoms that may appear singly or in combination. Viewed as resources, the first is exhaustion, which is a reduction in mental or physical resources. A second can be cynical detachment which is described as a reduction in social connectedness. The third is a reduced sense of efficacy or an erosion of value for oneself. In the WFH environment, to recover from burnout, employees need to assess which of the resources have fallen sharply, and return each to acceptable levels (Heng \& Schabran, 2021; Neeley, 2021; Sawhney, 2021; Tugan, 2020). It follows therefore, that burnout will remain an expected characteristic of the workforce's new normal.

Teams and Teamwork. Deployment of a more formalized hybrid HRM model also affects teams and teamwork. One drawback relates to the allocation of responsibility for positive organizational outcomes. Current remote work arrangements if maintained, would see the persistence of the tendency to give greater credit for a collective output to those who are more visible by virtue of being there in the office. Hybrid settings, it is maintained, are also linked to power differentials created within teams (Mortensen \& Haas, 2021).

Nevertheless, companies have always operated with teams, especially in the execution of high technology projects. Witness the participation of several companies, on a global scale, in the assembly of new models of aircraft, for example. It is of import to note too, that the disruption caused by the pandemic to the global medical supply chain has forced a reexamination of lean production strategy, bringing some elements of production back to workers in the US, with implications for employment and labor cost. The skills gap, nevertheless, persists. The workforce conditions imposed on companies by the pandemic in many parts of the world have resulted in networks of individuals operating as virtual teams. Teams, however, have their own peculiar set of challenges. Whereas, telework does have its positive effects, one of its drawbacks with respect to its use with teams going forward, can be its impact on trust and psychological safety.

Persistence with workforces lacking in-person interaction can rob some employees of the confidence, that they can let their voices be heard without fear of humiliation and punishment with respect to work content especially (see Edmondson \& Mortensen, 2021).

Taxation and Living Expenses. In the US, taxation levels differ from state to state. Work from anywhere or WFA as company policy, permits employees to work from different counties or states as a matter of choice, as individuals or as team members. The pandemic however, forced the decision on some workers to have their workplaces in different states of the US, while sheltering from less 
seriously COVID-19-affected cities in other states. For some workers, the taxation implications regarding residence may have to be taken on board. Double residency may mean "double taxation" of a single income.

Telework and Education. Although not all of the damage may be attributed to remote teaching, however, its use in combination with other factors have been associated with negative outcomes for some students in the American school system. At least one large school district reported an increase, way above the norm, in the number of F grades usually awarded. In this regard, it might be said, that remote teaching as a work category, has been found not to be a perfect substitute for in-person delivery. The State of Connecticut witnessed, for example, "F" grades being returned at four times the normal rate (Parish, 2021). Yet, hybrid (in-person and streaming) delivery of education may---in the short term---be one of the characteristics of the new work norm in education, once the internet access and broadband issues have been adequately addressed.

Internet Security. Whereas the lockdowns caused by the pandemic did show the resilience and productivity of the workforce to ably work remotely in a short space of time, this came at some cost in terms of outlays for computers (laptops) and related equipment. Not only was that attended by increases in demand for chips apart from those required for electric vehicles, it opened some companies to increased computer-related security risks (See Richter, 2020).

The worker's age or population group. Although not directly tied to remote work, per se, but linked to the future of work, the age of workers is significant in terms of disposition to work with implications for the size of the workforce. China is experiencing some reluctance on the part of some of its younger workers to work (Chen, 2021). Where previously in China, success was tied to working hard and getting married with children, the new "lying flat" trend with Chinese Gen Zers translates into foregoing marriage, remaining childless and staying unemployed. This is inclusive of the avoidance of material possessions such as automobiles and houses. What this entails also is a rejection of Chinese employers' expectations of the " 996 " work pattern (that is, working from 9 a.m. to 9 p.m., six days a week).

\section{Discussion and Conclusion}

The application of what has been referred to here as the Gratton Place-Time Framework enables the perspective that all work done as taking place along two dimensions represented on two axes: place and time. As suggested above, there exists a lingering mismatch in terms of the demand for labor and availability of certain skills that existed in certain sectors of the US economy---even before the pandemic. This disequilibrium of worker demand and supply, or what has been described elsewhere as worker absenteeism, has firms continuing to experience challenges in filling job openings. This will likely continue to exert pressure on the cost of labor-even as any of the disincentives caused by the Biden Administration's stimulus checks fade. As a partial response, automation is gaining steam in the fast-food industry, with drive-thru windows taking requests by way of voice recognition algorithms. In this regard too, some customers may not continue to be greeted by in-person human attendants in the future. Even ordering by telephone is beginning to displace waiter services (See Casselman, 2021).

Moreover, with respect to manufacturing, certain companies have already adopted a policy of involvement with certain schools to train would-be employees to close the skills gap. The new normal may also witness employee departures for entirely new job types. Such action might just be coming from those 
who consider themselves to be working too hard under current conditions such as, those being paid less than a living wage. Witness McDonald's recent wage increase response to its labor supply shortage. Current hybrid models, too, apparently remain very unfavorable to women with respect to careers (see The Economist, 2021). Yet, any near-term mitigation of some of the inherent biases against working mothers seems to depend on national vaccination efforts, addressing hesitancy, and the reopening of schools and restaurants. Together, these appear to have some impact on the willingness of women to return to work inperson, as part of the workforce. On the other hand, some aspects of the short-term labor market shortages for some categories of workers may be a function of the absence of fair-market wages in some sectors, and not a COVID-19-induced fear of the in-person workplace as such. Some workers, furloughed during the heights of the pandemic such as in the hospitality sector, may never return, switching to those job growth areas like digital sales, shipping, mortgage-financing and those business types that survived during the worst crisis periods (see Haddon et al., 2021).

The above discussion also highlights the fact that remote work is not suitable for all worker types. This is especially so for low wage earners. Vaccination efforts in the US, in particular, are leading some actors to shift their view of the pandemic as a short-term phenomenon, to one that is now manageable. The future of work therefore, calls for increasing adaptation on the part of both managers and their employees, as HRM becomes more formally and strategically decentralized, decoupling the office as the central workspace. Workers are expected to continue to work, as the 9-to-5 workers from the office, or the WFOs), from home (the WFHs), at anytime (as the ATWs) and from anywhere (the WFAs).

Generally speaking, low-wage blue-collar workers may not have too much choice in becoming either WFH or WFA employees, while, on the other hand, white-collar workers may continue to move into the gigging (and generally speaking, the WFA) economy. Some might engage in such parttime and remote work activity, just because it offers a source of supplementary income. Vaccination success and the termination of the unemployment insurance element of the stimulus package should mitigate some labor supply shortages, at the lower-wage levels. Therefore, policies must be put into place to discourage vaccine hesitancy in the short term, on the part of those reluctant to return to their pre-pandemic and in-person workplaces, because of safety and conditions of work issues. Hilsenrath \& Cambon (2021) attribute the short-term labor shortages to a mismatch between the place where certain jobs are and where workers are. Some workers have moved, have changed job preferences, are enjoying the non-commute to work, or are taking time to be more selective in making their new job choices. State apprenticeship programs may work to mitigate the worst impacts of these. Yet, in effect, what obtains is a short-term sellers' job market. Therefore, in certain sectors, signing bonuses may not be enough to incentivize workers to fill certain vacant positions.

If, however, the short-term low-wage labor scarcity persists, it can be expected that combined with prepandemic skills gap positions remaining open, the flight to technology substitutions with robotics is likely to intensify. Caution is therefore necessary regarding possible overgeneralizations regarding the emerging patterns, mainly because of the dynamic nature of the changes taking place in the work environment today, such as pending legislation, virus mutations, and the near inexorable technological changes taking place in the economy. Further, recognition must also be given to some of the forces at play working against those who are less visible, or who will have chosen the WFH option. This may be overcome with trust. Future research efforts therefore, need to discover the extent to which the quality of work-life has changed, since non-work issues like family and parenting have entered into the picture, with 
respect to structuring and scheduling in today's hybrid workforce models. It follows then, that those companies that have not addressed most of the remote work issues, however, will face increasingly, calls regarding agility, skill scarcity, flexibility, and the new needs for psychological safety regarding WFH and WFA workers, in particular. Companies, too, will have to continuously revisit and modify dynamically, their HRM policies.

Future research regarding remote work will also have to address the challenges of the new worklife balance issues. These would involve families, elderly parents and school-age children, where some schools may have already adopted short-term, or even long-term, hybrid teaching modalities. Research is also needed regarding the movement of different worker types along the time and place options selected, with respect to specific occupations and industries. Then, there is, too, the need to study the ramifications of wage price adjustments on the cost of labor, as led by some companies such as Amazon and McDonald's on the broader demand for labor. In addition, the residual effects of long COVID-19 on survivors with respect to labor productivity is an area for great concern and research. Last, but not least, is the need to study the role of the increasing incorporation of AI (artificial intelligence) into decision making, the deployment of man-plus-machine work teams in the production of goods and services regarding supply chain operations, and the impact of those issues on HRM. Looking at the big picture, the future of work is an evolving, very dynamic, and complex environment, with several moving parts, all in a technology-driven and highly competitive global marketplace.

\section{References}

Best, S. (2017). The U. S. gig economy: Economic imposition or economic choice. Abrm.com. (8): 6067.

BLS (2021). Unemployment rate. BLS. Retrieved from https://data.bls.gov/timeseries/CUSR0000SA0\&output_view=pct_1mth

Carucci, R. (2021, February 11). Is your midsize company designed for a post-pandemic future? HBR. Retrieved from https://hbr.org/2021/02/is-your-midsize-company-designed-for-a-postpandemic-

future?utm_medium=email\&utm_source=newsletter_daily\&utm_campaign=dailyalert_actsubs\&utm_c ontent=signinnudge $\&$ deliveryName=DM118652

Cassselman, B. (2021, July 04). Pandemic wave of automation may be bad news for workers. New York Times. Retrieved from https://www.yahoo.com/finance/news/pandemic-wave-automation-may-bad151513770.html

Chen, E. (202,1 July 03). These Chinese millennials are 'chilling,' and Beijing isn’t happy. New York Times. Retrieved from https://www.nytimes.com/2021/07/03/world/asia/china-slackers-tangping.html

Choudhury, P. R; Larson, B. Z; \& Foroughi, C. (2019). Is it time to let employees work from anywhere? HBR. Retrieved from https://hbr.org/2019/08/is-it-time-to-let-employees-work-fromanywhere

Clampa, D. (2021, February 25). A CEO's guide to planning a return to the office. HBR. 
Retrieved from https://hbr.org/2021/02/a-ceos-guide-to-planning-a-return-to-theoffice?utm_medium=email\&utm_source=newsletter_weekly\&utm_campaign=insider_activesubs\&utm _content=signinnudge $\&$ deliveryName=DM120882

Clayton, J. (2021). Remote working: Is Big Tech going off work from home? BBC.

Retrieved from https://www.bbc.com/news/technology-56614285

Dutcher, E. G. (2012). The effects of telecommuting on productivity: An experimental examination. The role of dull and creative tasks. Journal of Economic Behavior \& Organization, (84):355-363.

Edmondson, A. C. \& Mortensen, M. (2021, April 19). What psychological safety looks like in a hybrid workplace. HBR. Retrieved from https://hbr.org/2021/04/what-psychological-safety-looks-likein-a-hybridworkplace?utm_medium=email\&utm_source=newsletter_weekly\&utm_campaign=insider_activesubs \&utm_content=signinnudge \&deliveryName=DM129267

Everson, M., King, S. \& Ockels, E. (2021, July 13). Your company needs a digital nomad policy. Harvard Busines Review. Retrieved from https://hbr.org/2021/07/your-company-needs-adigital-nomadpolicy?utm_medium=email\&utm_source=newsletter_monthly\&utm_campaign=strategy_activesubs\&u tm_content=signinnudge $\&$ deliveryName=DM141138

Good, Brian (2021, March 31). 'Work from home' causing spike in gender and racial harassment according to survey from Ellen Pao's 'Project Include.' DiversityInc.

Retrieved from https://www.diversityinc.com/work-from-home-causing-spike-in-gender-and-racialharassment-according-to-survey-from-ellen-paos-projectinclude/?utm_medium=email\&_hsmi=118942025\&_hsenc=p2ANqtz-

97hYjqzwYtcF7_LhW_mBYV0SuavS3_97s1PhAPEo5jOBL1f7ZqG6_VADh6zazKe0QAWXap6wjwL0U3Lq0VyriP12neA\&utm_con tent $=118942025 \& u t m \_s o u r c e=h s \_$email

Gartner (2020, April 3). Gartner CFO survey reveals 74\% intend to shift some employees to remote work permanently. Gartner. Retrieved from https://www.gartner.com/en/newsroom/press-releases/2020-0403-gartner-cfo-surey-reveals-74-percent-of-organizations-to-shift-some-employees-to-remote-workpermanently2

Gartner (2021, March 23). Gartner says workplaces with shared seating will be the new normal after COVID-19. Gartner. Retrieved from https://www.gartner.com/en/newsroom/pressreleases/2021-03-23-gartner-says-workplaces-with-shared-seating-will-be-the-new-normal-aftercovid19

Gratton, L. (2021 May-June). Doing hybrid right. HBR. Retrieved from https://hbr.org/2021/05/how-to-do-hybridright?utm_medium=email\&utm_source=newsletter_weekly\&utm_campaign=weeklyhotlist_not_activ esubs\&deliveryName=DM128612 
Haddon, H., Chen, T. \& Weber, L. (2021, July 13). Customers Are Back at Restaurants and Bars, but Workers Have Moved On. Wall Street Journal. Retrieved from https://www.wsj.com/articles/customers-are-back-at-restaurants-and-bars-but-workers-have-movedon-11626168601?mod=hp_lead_pos6

Heng, Y. T. \& Schabran, K. (2021, April 12) Your burnout is unique. Your recovery will be, too. HBR. Retrieved from https://hbr.org/2021/04/your-burnout-is-unique-your-recovery-will-betoo?utm_source=pocket\&utm_medium=email\&utm_campaign=pockethits

Hilsenrath, J. \& Cambon, S. C. (2021, July 09). Job openings are at record highs. Why aren't unemployed Americans filling them? Wall Street Journal. Retrieved from https://www.wsj.com/articles/job-openings-are-at-record-highs-why-arent-unemployedamericans-filling-them-11625823021?mod=trending now news 4

K@W (2020, May 05). The post-crisis world: What changes are coming? Knowledge at Wharton. Retrieved from https://knowledge.wharton.upenn.edu/article/post-crisis-world-changescoming/

K@W (2021, March 23). Are you ready for the hybrid workplace? Knowledge at Wharton.. Retrieved from https://knowledge.wharton.upenn.edu/article/are-you-ready-for-thehybrid-workplace/?utm_source=kw_newsletter\&utm_medium=email\&utm_campaign=2021-03-23

Kalita, S. M. (2021, April). The rise of the independent worker: Why everyone wants to work in the gig economy now. Fortune. Retrieved from https://fortune.com/2021/04/21/gig-workers-covidindependent-contractors-remote-work-c-suiteexecutives/?utm_source=email\&utm_medium=newsletter\&utm_campaign=worksheet\&utm_content= $2021042121 \mathrm{pm}$

Morgan, K. (2021, March 07). Remote work has a lot of benefits, but one major drawback: It may be harder to climb the career ladder when you're at home. $B B C$. Retrieved from https://www.bbc.com/worklife/article/20210305-why-in-person-workers-may-be-more-likely-to-getpromoted

Mortensen, M. \& Haas, M. (2021, February 21). Making the hybrid workplace fair. HBR. Retrieved from https://hbr.org/2021/02/making-the-hybrid-workplace-fair

Moss, J. (2018). Helping remote workers avoid loneliness and burnout. HBR. Retrieved from https://hbr.org/2018/11/helping-remote-workers-avoid-loneliness-andburnout

Neeley, T. (2021). Remote work revolution. New York, NY: Harper Collins Publishers.

O’Hara, C. (2014). 5 Ways to work from home more effectively. HBR. Retrieved from https://hbr.org/2014/10/5-ways-to-work-from-home-moreeffectively?ab=at_art_art_1x1 
Parish, J. (2021, Sunday April 04). Education through the pandemic. The 74. Retrieved from https://www.yahoo.com/news/education-pandemic-four-fold-increase120100359.html

Richter, A. (2020). Lock-down digital work. International Journal of Information Management. 55: 1-3.

Sawhney, V. (2021). What do we like about WFH? HBR. Retrieved from https://hbr.org/2021/03/whatdo-we-like-about-wfh

Schwartz, J. \& Riss, S. (2021). Work Disrupted. HLockdown digital work.obeken, New Jersey: John Wiley \& Sons.

Sinform (2021, March 12). Remote work survey 2021: 82\% US-based companies offer permanent work from home. Sinform. Retrieved from https://www.simform.com/remote-work-survey-onepollsimform/

Sutherland, L. \& Nelson, J. (2020). Work Together Anywhere. Hobeken, New Jersey: John Wiley \& Sons.

The Economist (2021, February 20). When will office workers return? The Economist.

Retrieved from https://www.economist.com/business/2021/02/20/when-will-office-workersreturn?utm_campaign=the-economist-today\&utm_medium =newsletter\&utm_source=salesforcemarketing-cloud\&utm_term=2021-02-22\&utm_content=article-link-4\&etear=nl_today_4

Thiefels, J. (2021, April 23). 6 Things you must do if you're planning to work remotely permanently. Campus Fast Company. Retrieved from https://www.fastcompany.com/90628414/6things-you-must-do-if-youre-planning-to-work-remotelypermanently?partner=feedburner\&utm_source=feedburner\&utm_medium=feed\&utm_campaign=feed burner+fastcompany\&utm_content=feedburner\&cid=eem524:524:s00:04/23/2021_fc\&utm_source=n ewsletter\&utm_medium=Compass\&utm_campaign=eem524:524:s00:04/232021_fc

Thomas, P. \& Benoit, D. (2021, Jul 03). Wall Street wants bankers back in the office, especially genzers. Wall Street Journal. Retrieved from https://www.wsj.com/articles/wall-street-wants-bankersback-in-the-office-especially-gen-zers-11625304601?mod=hp_lead_pos8

Walker, O. (2021, June 28). UBS seeks hiring edge over Wall St with home-office mix for most staff. Financial Times. Retrieved from https://digital.olivesoftware.com/Olive/ODN/FTUS/Default.aspx 